\title{
PEMANFAATAN KALI MATI SEBAGAI MEDIA PEMBUATAN KOLAM WARING DI DESA IRINGMULYO, METRO TIMUR, KOTA METRO
}

\author{
Dwi Irawan¹, Yusuf Amran²
}

\begin{abstract}
Abstrak: Berdasarkan analisis situasi, permasalahan mitra dan hasil diskusi bersama persoalan prioritas yang dialami warga RT. 26 dan RT. 27 Desa Iringmulyo, Metro Timur, Kota Metro adalah kumuhnya kali mati yang tidak dimanfaatkan dan hanya sebagai tempat pembuangan sampah oleh sebagian warga. Adapun metode pendekatan yang ditawarkan untuk menyelesaikan persoalan mitra antara lain: Membersihkan Kali Mati, Membuat Kolam Waring Ikan, Pemberian Modal Usaha Untuk warga. Tujuan program Iptek bagi Masyarakat (IbM) ini adalah lingkungan sekitar kolam menjadi nyaman, bersih, dan warga ada pemasukan tambahan secara ekonomi dari budidaya ikan. Utamanya adalah mengurangi pencemaran lingkungan dan membuat warga enggan untuk membuang sampah di kali mati tersebut, serta terjadi peningkatan kesejahteraan untuk warga. Dari kegiatan ini menghasilkan Kali Mati menjadi bersih, terbentuknya kelompok ikan (Pokdakan) yang diberi nama "Metro Bintang Timur", dan sudah mempunyai badan hukum yang resmi, terbuatnya kolam waring ikan sejumlah 6 waring dengan fondasi utama adalah drum plastik jadi waring terapung dan apabila air naik, waring ikut naik dan tidak terjebak banjir. Pokdakan tersebut diberi modal berupa bibit ikan lele dan pakan ikan untuk pengembangan dan tahap pendampingan sampai panen.
\end{abstract}

Kata Kunci: Ekonomi, IbM, Kali Mati, Waring Ikan.

\section{The Utilizing Dead River as Medium Building of Waring Pond in Iringmulyo Village, Metro Timur, Metro City}

Abstract: Based on situation analysis, client problem and joint discussion result, the priority problem that experienced by inhabitants of RT. 26 and RT. 27 Iringmulyo Village, sub-district of Metro Timur, Metro City is untidiness of dead river that is not utilized and only used as laystall by some inhabitants. The promoted approach methods to solve this clien problem are: cleaning dead river, building nets fish pond, and provision of venture capital to inhabitants. By conducting these IbM program, it is expected for comfort and cleanliness of environment around river, increasing of inhabitant's economic income by fish cultivation. The foundational of problem solving is to reduce environmental pollution and to prohibit inhabitant for throwing rubbish into dead river and enhancement of inhabitant prosperity. This activity has made dead river cleans, fishing group (Pokdakan) is formed named "Metro Bintang Timur" that has legality evidence, 6 nets fish pond is built where main foundation is plastic drum where if flood comes, the nets will float and unstuck. The pokdakan is given capital of fingerlings of catfish and fish feed for development and mentoring phase till the harvest time.

Keywords: Dead River, Economy, IbM, Waring Pond.

\section{PENDAHULUAN}

Kali mati adalah sungai yang tidak lagi mengalir airnya. Sementara ini kali mati biasa dijadikan tempat pembuangan sampah oleh sebagian warga

\footnotetext{
${ }^{1}$ Fakultas Teknik Universitas Muhammadiyah Metro; email: dwi_irawan@yahoo.co.id.

${ }^{2}$ Fakultas Teknik Universitas Muhammadiyah Metro; email: yusufamran@yahoo.com.
} 
setempat, dan dibiarkan saja, tidak dimanfaatkan. Karena sampah warga banyak yang dibuang, mengakibatkan kali mati menjadi bau dan kumuh. Kali mati tersebut terlihat kotor, tidak terawat, dan lingkungan menjadi tercemar. Kualitas lingkungan turun yang menyebabkan lingkungan menjadi kurang atau tidak dapat berfungsi lagi sesuai dengan peruntukannya, karena masuknya atau dimasukkannya makhluk hidup (organisme), zat, energi, atau komponen lain ke dalam lingkungan, dan berubahnya tatanan lingkungan oleh kegiatan manusia, atau proses alam. Masyarakat tidak menyadari bahwa dampak yang ditimbulkan dari pencemaran tersebut akan merusak lingkungan sekitar, udara menjadi bau, dan mencemari air tanah.

Upaya yang telah dilakukan oleh warga sekitar, kali mati tersebut pernah dibuat kolam waring, tetapi sudah tiga tahun yang lalu tidak berjalan lagi. Warga masih belum bisa mengelola usaha tersebut. Usaha warga hanya berjalan sekitar satu, setelah itu, mati suri dan tidak berjalan lagi. Studi awal menyebutkan bahwa ketidaksuksesan usaha kolam waring yang dijalani warga, karena beberapa faktor, seperti pengetahuan warga masyarakat yang kurang tentang budidaya ikan air tawar, pemahaman warga tentang kebersihan lingkungan hidup yang belum memadai, dan yang utama adalah karena kondisi air kali mati yang sudah tercemar, seperti tampak pada Gambar 1.

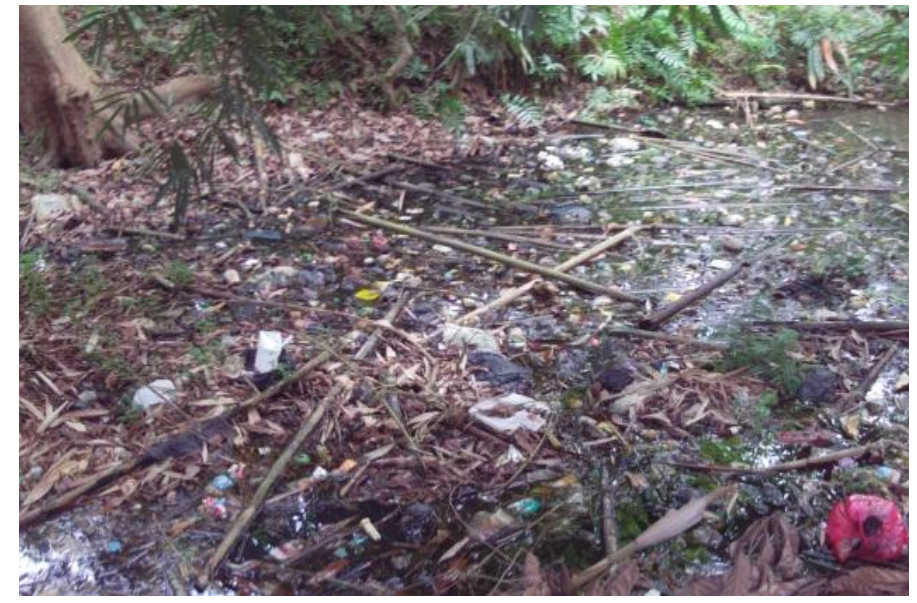

Gambar 1. Kondisi Kali Mati

Melihat kondisi kali mati, mendesak untuk segera dibersihkan agar penumpukan sampah berkurang, mengurangi pencemaran lingkungan dan air kali menjadi bersih. Setelah bersih, kali dapat dimanfaatkan untuk membuat kolam waring ikan. Sistem kolam ini adalah waring yang dipasang di kali dan diberi dudukan pengait pada ujung-ujung waring. Kali mati tersebut berpotensi untuk menghasilkan nilai tambah, yaitu nilai kebersihan lingkungan hidup, meningkatkan nilai ekonomi. Melihat lokasi yang sangat luas jadi apabila dibuat kolam waring ikan dapat beberapa kolam. 


\section{METODE PELAKSANAAN}

Pengabdian dilaksanakan RT. 27 RW. 12 Kelurahan Iringmulyo Kecamatan Metro Timur Kota metro. Kegiatan pengabdian yang dilakukan, meliputi: 1) Pembentukan kelompok budidaya ikan (Pokdakan); 2) Pembersihan kali mati; 3) Pembuatan kerangka kolam apung; 4) Perakitan kolam apung; dan 5) Sosialisasi kebersihan lingkungan.

\section{HASIL DAN PEMBAHASAN}

Kegiatan Ipteks bagi Masyarakat (IbM) dilakukan pertama kali adalah memberikan pemahaman kepada warga untuk membangkitkan kembali kegiatan usaha perikanan yang mati suri melalui pembentukan kelompok budidaya ikan (Pokdakan). Masyarakat diyakinkan, jika pola usaha dilakukan dengan benar, maka hasil yang diperoleh dapat optimal. Masyarakat berhasil diinisiasi untuk membentuk kelompok budidaya ikan (Pokdakan) di RW 12 yaitu warga RT 26 dan RT 27 yang diberi nama Metro Bintang Timur, yang terdiri dari 10 warga dan telah disahkan dan mempunyai badan hukum dengan nomor AHU-0066782.AH.01.07.Tahun 2016. Sebagian kelompok sudah didaftarkan ke Dinas pertanian, peternakan dan perhutanan kota metro untuk dibuatkan Tanda Pencatatan Usaha Pembudidayaan Ikan (TPUPI).

Selanjutnya, untuk memulai usaha perikanan di kali mati yang sudah tercemar, masyarakat bersama-sama diajak untuk membersihkan kali mati dari tumpukan sampah dan limbah lain. Melalui kegiatan ini, kali mati di RT $26 \mathrm{RW}$ 12 Desa Iringmulyo yang awalnya banyak menumpuk sampah-sampah dari warga sekitar sekarang menjadi bersih dengan dilakukan pembersihan kali tersebut. Kesadaran warga untuk membersihkan kali mati karena penambahan pemahaman warga dan Pokdakan tentang pentingnya kebersihan lingkungan beserta dampaknya apabila lingkungan itu kumuh dan tidak terawat. Gambar 3 memperlihatkan masyarakat membersihkan kali mati yang kotor.

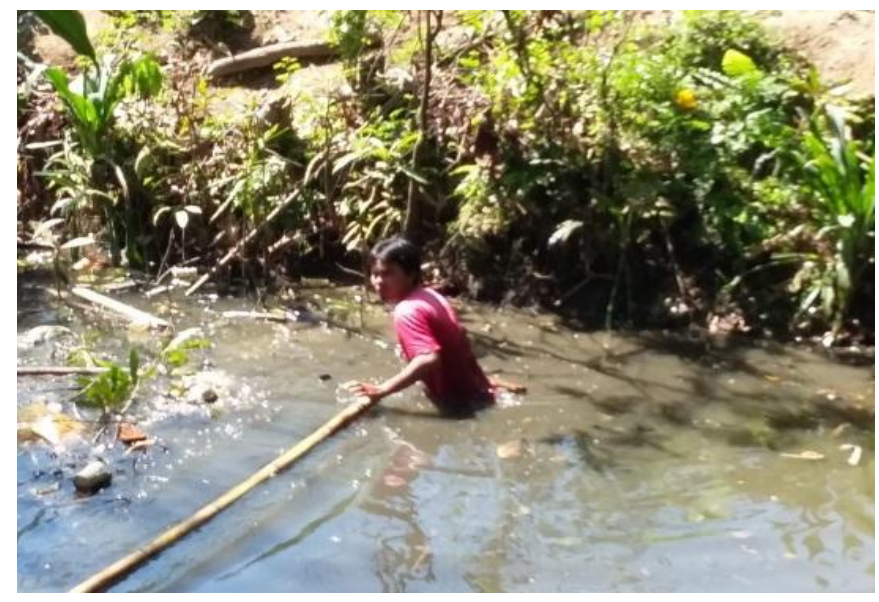

Gambar 2. Pembersihan Kali Mati oleh Masyarakat 
Setelah kali mati menjadi bersih dan memadai untuk menjadi tempat budidayakan ikan, kemudian mulai menyiapkan waring sebagai media buddaya ikan. Masyarakat dilatih membuat waring sendiri dengan mengikuti ketentuan, yaitu lembaran kain jaring dipotong sesuai dengan ukuran potongan yang dikehendaki yaitu panjang $\times$ lebar $\times$ tinggi $=6 \times 3 \times 2 \mathrm{~m}$. Kemudian kain jaring dijahit dibentuk kantong jaring sesuai dengan ukuran tersebut. Disamping kantong dibentuk disesuaikan dengan bentuk KJA, kantong jaring bagian tepinya juga dijahit sebagai tempat tali ris yang berfungsi untuk menggantungkan kantong jaring pada kerangka KJA.

Desain dan konstruksi bangunan kolam jaring apung hingga sekarang banyak mengalami perubahan dan penyesuaian. Sehingga bangunan dan konstruksi tidak tertentu. Konstruksi kolam jaring apung secara umum banyak memerlukan bahan berupa bambu. Tetapi kini peran bambu tersebut telah diganti dengan besi sehingga lebih tahan lama walaupun biayanya menjadi mahal. Pengapung yang dipergunakan bisa berupa drum zenk bekas, drum plastik atau styrofoam. Waring dipasang/dirakit di lokasi dengan cara: 1) Menghubungkan antar waring; 2) Menempatkan kerangka kolam; 3) Memasang kantong jaring; dan 4) Memasang jangkar. Gambar 3 memperlihatkan kegiatan merakit kerangka kolam yang dilakukan masyarakat.

Kegiatan pembuatan waring berhasil membuat enam kolam waring untuk media pembudidayaan ikan air tawar, agar menjadi tambahan pendapatan untuk warga sekitar. Waring tersebut dibuat di kali mati dengan media drum plastik dan diberi bambu untuk berjalan juga untuk tempat dudukan waring, seperti dilihat pada Gambar 4.

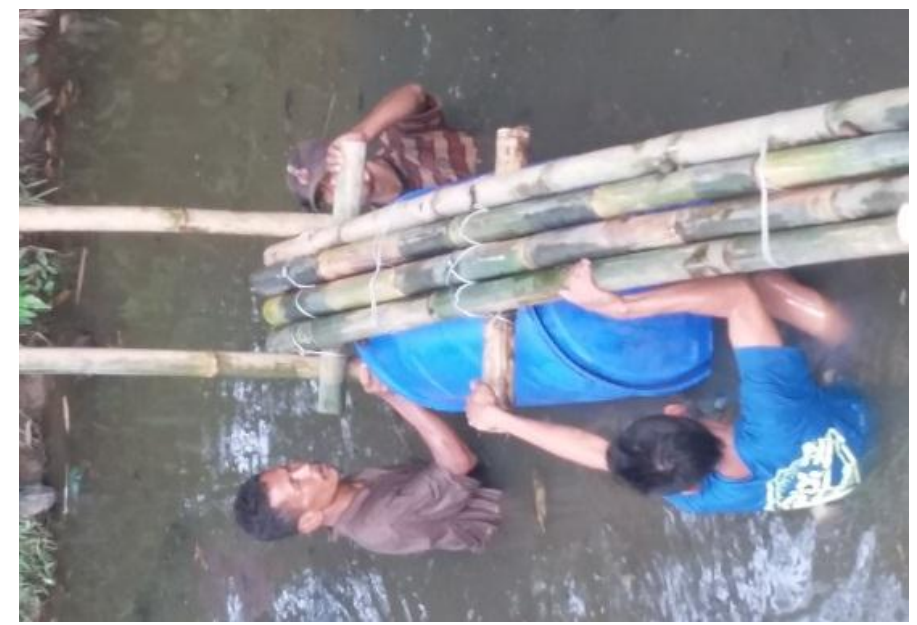

Gambar 3. Perakitan Kerangka Kolam 


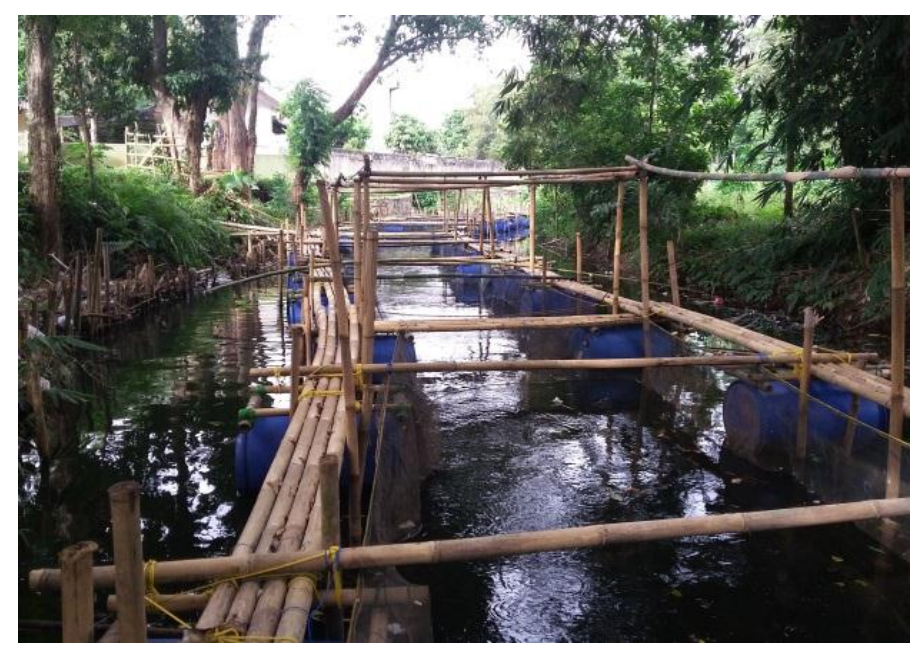

Gambar 4. Kolam Waring Apung

Lahan dan media yang sudah siap, saatnya untuk memulai usaha perikanan. Hasil diskusi dengan Pokdakan dan analisis yang dilakukan, maka jenis ikan yang dipilih untuk dibudidayakan adalah ikan lele. Melalui bantuan dinas terkait, masyarakat yang sudah terdaftar dalam kelompok diberikan modal untuk pembibitan ikan lele dan pakan ikan agar mereka bisa mulai budidaya ikan tersebut. Agar modal usaha lebih berdayaguna, pemerintah melalui Dinas Perikanan Kota Metro melakukan sosialisasi (Gambar 5) tentang cara budidaya ikan lele, analisis usaha, dan sebagainya. Pokdakan yang diberi modal berupa bibit ikan lele (Gambar 6) dan pakan ikan untuk pengembangan, juga dilakukan pendampingan sampai panen.

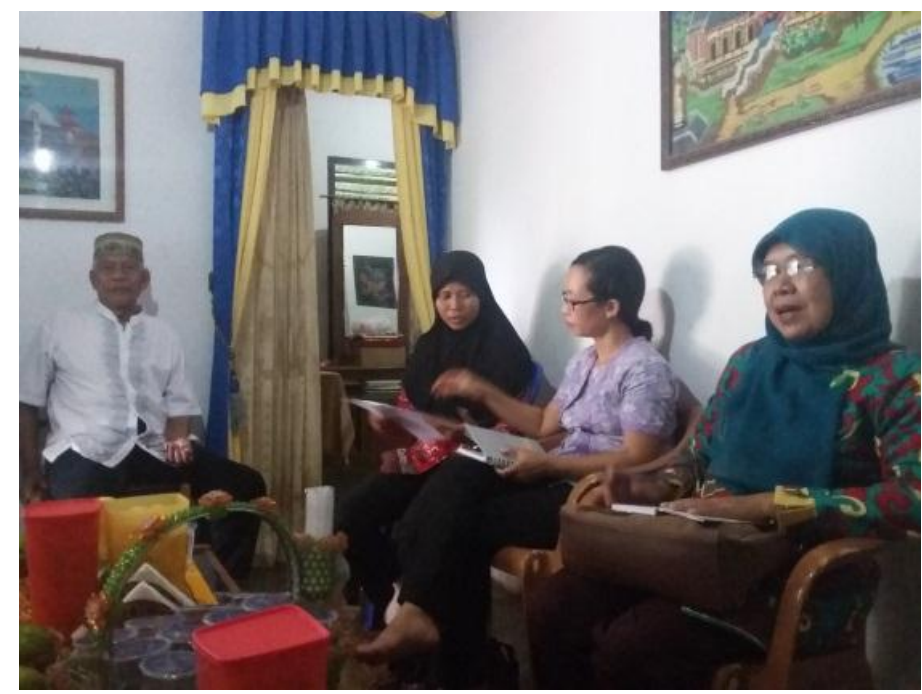

Gambar 5. Sosialisasi oleh Dinas Pertanian, Perikanan, dan Perhutanan 


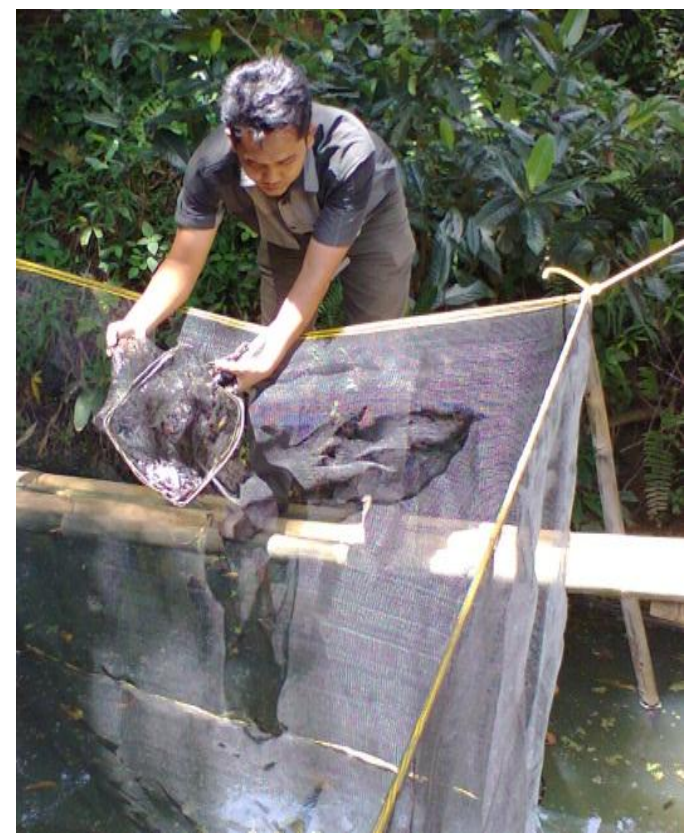

Gambar 6. Penebaran Bibit lkan Lele

\section{KESIMPULAN}

Sesuai tujuan diselenggarakannya program IbM ini adalah lingkungan sekitar kolam menjadi nyaman, bersih, dan warga ada pemasukan tambahan secara ekonomi dari budidaya ikan. Maka, berdasarkan tahap-tahap yang sudah dilakukan kegiatan IbM ini mampu menghasilkan: 1) kali mati menjadi bersih dan bebas penumpukan, sehingga kali dapat dimanfaatkan; 2) Terbentuknya kolam waring apung dari drum plastik untuk budidaya ikan air tawar agar menambah pendapatan warga; 3) Terbentuknya kelompok ikan (Pokdakan) yang diberi nama "Metro Bintang Timur" sebagai wadah budidaya ikan yang ada di RT. 26 dan RT. 27 Desa/Kelurahan Iringmulyo; 4) Pokdakan yang terbentuk telah berbadan hukum dan mempunyai Tanda Pencatatan Usaha Pembudidaya Ikan (TPUPI) dari dinas Pertanian, Perikanan, dan Perhutanan Kota Metro; dan 5). Pokdakan bisa membudidayakan ikan air tawar dengan diberikan modal berupa ikan lele dan pakan ikan. Kegiatan IbM dilanjutkan dengan pendampingan sampai panen.

\section{REFERENSI}

Adi, S. (2013). Budi daya lele ternak apung. [Online]. Tersedia: http://ternaklele-mudah.blogspot.com. [20 Maret 2015].

Fauzi, A., \& Anna, S. (2005). Pemodelan sumber daya perikanan. Jakarta: Gramedia Pustaka Utama. 
Pemanfaatan Kali Mati Sebagai Media Pembuatan Kolam Waring di Desa Iringmulyo, Metro Timur, Kota Metro

Sani, B. (2014). Budidaya ikan gurami. Yogyakarta: Dafa Publishing.

Anonymous. (2013). Waring (jaring untuk ikan). [Online]. Tersedia: https://fjb.kaskus.co.id/product/514bc04905346a636100000e/jualwaring-jaring-untuk-kolam-ikan-2m×3m×12m. [20 Maret 2015]. 